\title{
əHow to Deal with Heat Stress at an Open-Air Event? Exploring Visitors' Vulnerability, Risk Perception, and Adaptive Behavior with a Multimethod Approach
}

\author{
Anna Heidenreich, ${ }^{\mathrm{a}}$ Martin Buchner, ${ }^{\mathrm{a}}$ ARIAne Walz, ${ }^{\mathrm{a}}$ AND AnNegret H. Thieken ${ }^{\mathrm{a}}$ \\ ${ }^{\mathrm{a}}$ Institute of Environmental Science and Geography, University of Potsdam, Potsdam, Germany
}

(Manuscript received 5 February 2021, in final form 6 August 2021)

\begin{abstract}
Heat waves are increasingly common in many countries across the globe, and also in Germany, where this study is set. Heat poses severe health risks, especially for vulnerable groups such as the elderly and children. This case study explores visitors' behavior and perceptions during six weekends in the summer of 2018 at a 6-month open-air horticultural show. Data from a face-to-face survey $(n=306)$ and behavioral observations $(n=2750)$ were examined by using correlation analyses, ANOVA, and multiple regression analyses. Differences in weather perception, risk awareness, adaptive behavior, and activity level were observed between rainy days (maximum daily temperature $<25^{\circ} \mathrm{C}$ ), warm summer days $\left(25^{\circ}-30^{\circ} \mathrm{C}\right)$, and hot days $\left(>30^{\circ} \mathrm{C}\right)$. Respondents reported a high level of heat risk awareness, but most $(90 \%)$ were unaware of actual heat warnings. During hot days, more adaptive measures were reported and observed. Older respondents reported taking the highest number of adaptive measures. We observed the highest level of adaptation in children, but they also showed the highest activity level. From our results we discuss how to facilitate individual adaptation to heat stress at open-air events by taking the heterogeneity of visitors into account. To mitigate negative health outcomes for citizens in the future, we argue for tailored risk communication aimed at vulnerable groups.

SIGNIFICANCE STATEMENT: People around the world are facing higher average temperatures. While higher temperatures make open-air events a popular leisure time activity in summer, heat waves are a threat to health and life. Since there is not much research on how visitors of such events perceive different weather conditions-especially hot temperatures-we explored this in our case study in southern Germany at an open-air horticultural show in the summer of 2018. We discovered deficits both in people's awareness of current heat risk and the heat adaptation they carry out themselves. Future research should further investigate risk perception and adaptation behavior of private individuals, whereas event organizers and authorities need to continually focus on risk communication and facilitate individual adaptation of their visitors.
\end{abstract}

KEYWORDS: Extreme events; Adaptation; Communications/decision making; Emergency preparedness; Emergency response; Field experiments; Societal impacts

\section{Introduction}

The past decade was the hottest in the history of weather observation (World Meteorological Organization 2020). As a result of global warming, heat waves have increased in numbers and intensity worldwide (Coumou and Rahmstorf 2012) and have gained a higher probability of occurrence in the future (Field et al. 2012; Pachauri et al. 2014). The year 2020 has been the hottest year on record for the Northern Hemisphere (Centre for Research on the Epidemiology of Disasters 2021). In central Europe, where this study is set, heat waves are not only likely to occur more often, they will presumably last longer and be more intense (Fischer and Schär 2010).

Many implications of heat stress on human functioning and well-being are discussed in literature. Heat can demonstrably lead to implied cognitive functioning (Cedeño

\footnotetext{
D Denotes content that is immediately available upon publication as open access.
}

Corresponding author: Anna Heidenreich, annaheidenreich@ uni-potsdam.de
Laurent et al. 2018), a higher level of aggression and conflict (Hsiang et al. 2013; Anderson 2016), an increase in suicide rates (Burke et al. 2018), and a substantial labor force loss (Zander et al. 2015; Borg et al. 2021). Extreme heat poses a severe health risk: In 2021, heat waves were the deadliest disaster events worldwide (Centre for Research on the Epidemiology of Disasters 2021). Depending on sociodemographic variables, some people are especially vulnerable to suffering from heat. Key risk factors are very young or old age and preexisting health problems (Koppe et al. 2004; Schuster et al. 2017; World Health Organization 2021b). Heat waves are, however, a threat to the general public as a whole (Kunz-Plapp et al. 2016).

Germany, where this study is set and which is usually characterized by a temperate climate, recently experienced rising numbers of heat days and local maxima above $40^{\circ} \mathrm{C}$ to which German residents are not adapted (Matzarakis et al. 2020). Germany will face more weather extremes in the near future: in the upcoming decades, more heat waves will occur while the probability of cold spells decreases (Jacob et al. 2014; Dalelane and Deutschländer 2013). Extreme heat-days with maximum temperatures of $30^{\circ} \mathrm{C}$ and above are considered hot days in Germany (Deutscher Wetterdienst 2020b) — has evidently led to a substantial increase 
in hospital admissions and deaths in Germany (Karlsson and Ziebarth 2018; der Heiden et al. 2019).

Open-air events and festivals of all sorts are much beloved leisure activity during the warm and sunny season. In temperate climates, steadily high temperatures allow a variety of outdoor activities but also pose a health threat especially for risk groups, such as children and the elderly. The World Health Organization (2021a) defines people aged 60 years and over as older persons. In this article we discuss risk perception and individual adaptive behavior to heat stress among visitors of a horticultural show. With this case study we aim at deriving recommendations that make future open-air events safer and more enjoyable for all age groups.

\section{Current research on risk perception and adaptive behavior}

\section{a. Heat appraisal and risk perception}

Shooshtarian et al. (2018a) reviewed literature on thermal adaptation in outdoor spaces. The authors summarized three clusters of adaptive strategies: environmental and technological modifications, behavioral adjustments, and psychological adaptation. Individual adaptive behavior to heat stress is crucial in preventing negative health consequences and deaths. The World Health Organization $(2011,2021 b)$ recommends a number of measures to the general public, such as keeping one's home cool through shading or air conditioning, avoiding the heat by staying in shaded places or avoiding strenuous activities during the hottest time of the day, and keeping the body cool by wearing light, loosefitting clothing and drinking hydrating fluids regularly.

Most of the advised adaptive behaviors are presumably neither surprising nor new to the general public. However, do people perceive long-lasting heat as a serious problem, as a risk that is relevant to them personally and that requires adaptation of behaviors? There is a broad range of literature on the perception of risks (Slovic 1987; Breakwell 2014). In recent years, research on risk perception in the specific field of natural hazards has flourished.

In different major European cities, a research team conducted brief street surveys on people's heat risk perception (Gil Cuesta et al. 2017; van Loenhout and Guha-Sapir 2016): In Madrid, Spain; Lisbon, Portugal; Brussels, Belgium; and Amsterdam, Netherlands, pedestrians were surveyed on their knowledge of vulnerable groups and the impact of heat stress. Having a low level of education and status as a foreigner in the city, were identified as two factors that were associated with lower levels of knowledge and awareness in the studies. Different aspects varied across the four cities, but the authors concluded that the general level of knowledge on heat stress and heat risk awareness needs to be fostered in all areas, and especially vulnerable groups need to be targeted (Gil Cuesta et al. 2017; van Loenhout and Guha-Sapir 2016).

Set in the German city of Karlsruhe, a survey among 323 residents (Kunz-Plapp et al. 2016) delivered insights into the perception of heat stress and the experience of impacts of heat. The authors report that respondents from all age groups and with different health conditions suffered from the impacts of heat stress in one way or another. Most respondents reported applying simple coping measures like drinking more fluids or wearing light clothing rather than changing their daily routines by, for example, shifting work/activities or seeking cooler places. In places of everyday life, the perception of heat stress differed: while public transportation, homes at night, and the city center were described as places with high levels of heat stress, outdoor parks, gardens, pools, cars, and shopping areas represented comparably comfortable places (Kunz-Plapp et al. 2016).

Certain groups that are especially vulnerable to heat stress are more frequently addressed in public health interventions (Mayrhuber et al. 2018). The necessity of tailored approaches is highlighted in a number of international studies finding a lack of risk perception in the general population (Howe et al. 2019; Akompab et al. 2013) and among the elderly (Wolf et al. 2010; Bittner and Stößel 2012; Abrahamson et al. 2009; Howe et al. 2019).

\section{b. Outdoor heat risk behavior}

Environmental impacts and sustainability of cultural events are a core public interest and thus also a focus of event research (Mair and Whitford 2013). There are a number of observational studies that investigated the impact of microclimate on activity levels in public open spaces. Extreme hot and cold temperatures are generally linked to reduced activity (Lin 2009; Thorsson et al. 2007; de Montigny et al. 2012). Other studies confirm that the measured microclimatic conditions account for most of the variance in activity levels in public spaces and further report that providing sheltered seating areas increased the number of people sitting relative to unsheltered seating (Zacharias et al. 2001, 2004).

In recent years, research interest on human thermal perception and thermal comfort has grown (Franck et al. 2013; Lenzholzer and van der Wulp 2010). Based on an in-depth investigation into thermally comfortable urban spaces in the city of Amsterdam via microclimatic measurements and field surveys, Klok et al. (2019) identified that shading most effectively reduced heat stress, which is a noteworthy insight for open-air events.

To date, Australia has a considerable lead in research on outdoor heat risk behavior. Sharifi and Boland (2018) investiated outdoor activities in different areas of the city of Adelaide. Using data from activity observations and microclimatic measurements the authors discovered a decrease in optional and social activities above the neutral thermal threshold of universal thermal climate index (UTCI) $=34^{\circ} \mathrm{C}$. They further define a critical zero-activity threshold at $48^{\circ} \mathrm{C}$. Dismissing certain activities thus can be seen as behavioral adaptation. Shooshtarian et al. (2018b) report on an observational study at a university campus in Melbourne. They discuss seasonal differences in location preference and usage patterns based on survey data, unobtrusive observation, and microclimatic measurements.

\section{c. Focus of this research}

The aim of this article is to explore visitors' risk appraisal and their adaptive behavior in the context of a major open-air event during different weather conditions in Germany. There 
TABLE 1. Time schedule on each observation day.

\section{Method}

0930-1200 local time

First round of observations, with one observation at each of the four locations (Fig. 2) with the following procedure: 1) approaching the location and setting up the equipment, 2) behavioral observation (15 min), 3) microclimatic measurements and visitor count at the location, and 4) packing up the equipment and walking to the next location

1230-1445 local time Second round of observations, with one observation at each of the four locations and using the same procedure as in the first round

1500-1800 local time

Face-to-face survey, with one researcher at each entrance/exit area (see Fig. 2)

is a call for research on heat as a natural hazard in social science. Heat stress is far less explored than, for example, flooding and hurricanes as a recent meta-analysis of factors involved in climate change adaptation behavior shows (van Valkengoed and Steg 2019). To the best of our knowledge, risk appraisal and adaptation at an open-air event have not been explored in a combined approach, so far. We investigate the visitors' heat risk awareness and their behavior at the event site during extreme heat $\left(\geq 30^{\circ} \mathrm{C}\right)$ in comparison with other weather conditions. Based on our findings, we derive recommendations for organizers of future events and other stakeholders in heat risk management, in order to improve the health and safety of all visitors and employees.

Since age is one of the main predisposing factors for heatrelated illness, we will focus particularly on vulnerable age groups. For one thing, the elderly (i.e., people aged 60 and over) are more vulnerable to suffering from heat stress due to intrinsic changes in their regulatory system, low fitness levels, and a relatively high percentage of people with illnesses and disabilities within the age group (World Health Organization 2021b). Besides that, it is also suggested that children and infants are at higher risk of heat-related death (Vanos 2015). In this study, we therefore investigate 1) how age affects individuals' weather appraisal and heat risk perception and 2) how age and weather appraisal together explain adaptive behavior.

\section{Methods and data}

The study was carried out in 2018, which has been the hottest year recorded in Germany so far (Deutscher Wetterdienst 2020a). We applied a multimethod approach, which allowed us to explore the visitors' perception of and response to heat stress by means of both observed (via behavioral observations) and self-reported behavior (via questionnaires). To categorize the observation days in terms of heat stress, we carried out microclimatic measurements. The time schedule for each observation day is illustrated in Table 1 and explained below. The official heat warnings were given by the German Meteorological Service [Deutscher Wetterdienst (DWD)], which is operating the official German heat health warning system (HHWS; Matzarakis et al. 2020).

\section{a. Setting}

The Landesgartenschau is a regional horticultural show that is hosted by different German cities biennially aiming to support sustainable urban development. In 2018 a Landesgartenschau took place in the city of Würzburg, Bavaria. It opened on 12 April and closed its gates on 7 October. Over this 6-month period, around 700000 people visited the event (WürzburgWiki 2020).

Set in an area of former U.S. military barracks, the exhibition grounds covered approximately $28 \mathrm{ha}$. There were different types of areas, such as unshielded meadows, shade-providing woodlands, and also interior spaces like restaurants and exhibition rooms. We decided to carry out the behavioral observations at four fixed locations, which differed in both sun exposure and type of usage (Fig. 1).

Location 1 was a small sports field where children and adults could play basketball or other games. It was surrounded by trees that provided shade. A water feature (i.e., an artificial pond) and a surrounding walk characterized location 2. This location was in full sun. The water feature was used by visitors to walk through and play. Location 3 was a hilly green area with grouped parasols and deck chairs. Visitors were expected to come here to take a break and sit in the shade. Location 4 was a playground that offered no sun protection (Fig. 1).

\section{b. Data collection}

\section{1) BEHAVIORAL OBSERVATIONS}

Observations were conducted at four different locations (Fig. 1) on the event site between 0930 and 1445 local time during six consecutive weekends between 7 July and 12 August 2018. Each station was observed twice on each of the 12 observation days. Each observation was carried out by a team of two researchers: one observed, while the other kept records using a standardized observational protocol divided into two parts: The first part covered general data like time, visitor count, and microclimatic measurements (see below). The second part included the actual behavioral observation, which lasted about $15 \mathrm{~min}$ : visitors were described individually, with regard to their sex, (estimated) age group, visible heat adaptation measures, and activities (Table 1). The adaptation measures (wearing a head covering, carrying a drink, staying in the shade, carrying a parasol or umbrella, wearing short clothing, and wearing light clothing) were summed up to derive a heat adaptation level (Table 2). Each observed person could potentially exhibit up to all six adaptation measures and thus obtain an adaptation level between 0 and 6 . Further recorded measures were not included in this index because they were associated with either rain or cold adaptation (wearing a jacket or weather-proof clothing) or they were only observable at location 2 (playing or walking in the water). The observed activities (Table 2) were categorized into an activity 
Location 3: Green space

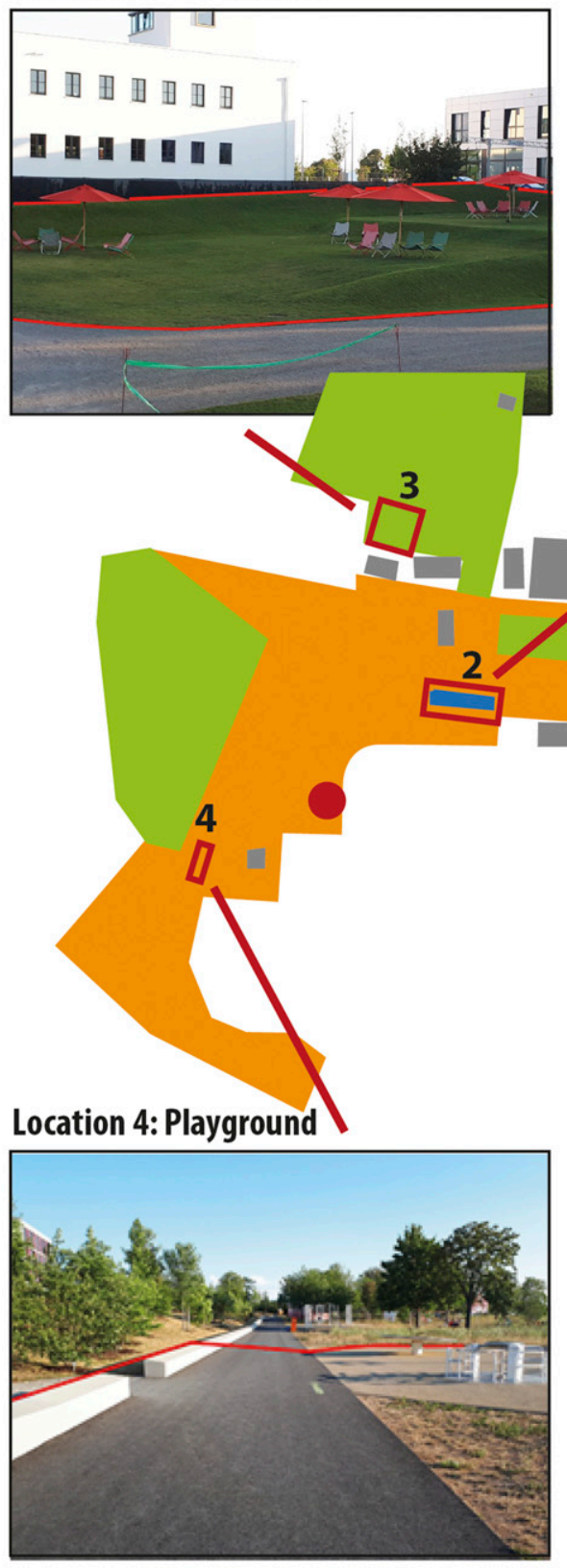

\section{Location 2: Water feature}

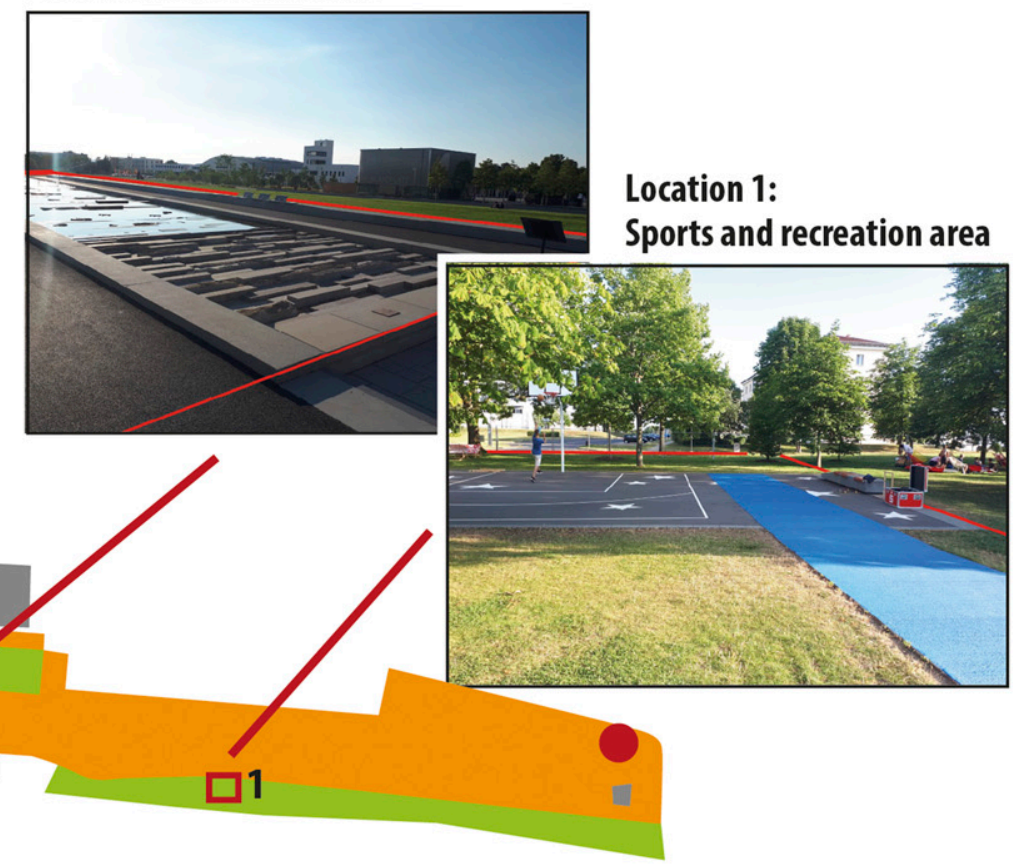

Full sun exposure

Shade and half-shade (trees, parasols)

Interior areas

Water area

Observation Point

Survey area at entrance/exit

FIG. 1. Observation locations and survey areas.

level index, smaller values indicating lower level of activity (e.g., being calm or resting) and higher values indicating higher level of activity (e.g., activities with strong physical exertion). The activity index ranged from 0 (calm activity) to 3 (strong physical exercise). If a person carried out more than one activity simultaneously, the higher activity level was assigned.

\section{2) Microclimatic MEASUREMENTS}

Wet-bulb temperature and dry-bulb temperature were measured using an Assmann aspiration-type psychrometer (Fig. 2). The device provides a measurement range from $-10^{\circ}$ to $+60^{\circ} \mathrm{C}$, a humidity measuring range of up to $100 \%$ relative humidity with an accuracy of $1 \%$ and a thermometer graduation of $0.2^{\circ} \mathrm{C}$ (Fischer 2005). It was operated for $3 \mathrm{~min}$ at a height of $1.5 \mathrm{~m}$ above the ground surface.

To categorize the observation days, we measured dry- and wet-bulb temperatures of the area directly after every behavioral observation. For assessing thermal perception, numerous indices of human thermal climate are discussed in the literature (de Freitas and Grigorieva 2017). We decided to use the heat index (HI) following Rothfusz (1990), applying the following formula: 
TABLE 2. List of adaptation measures and categorized activities measured during observation.

\begin{tabular}{ll}
\hline Adaptation measures & $\begin{array}{l}\text { Head covering, }{ }^{\text {a }} \text { drink, }{ }^{\mathrm{a}} \text { in shade, }{ }^{\mathrm{a}} \text { parasol/umbrella, }{ }^{\mathrm{a}} \text { short clothing, }{ }^{\mathrm{a}} \text { light clothing, }{ }^{\mathrm{a}} \text { in water, jacket, and/or } \\
\text { Activity level }\end{array}$ \\
& $\begin{array}{l}\text { indicates calm activity: sitting, standing, lying on the ground, eating, and/or drinking } \\
1 \text { indicates modest activity: walking, playing calmly, carrying something, carrying a child, and/or singing }\end{array}$ \\
& 2 indicates sporty activity: using playground equipment, riding bike/scooter, or playing badminton \\
& 3 indicates strong physical exercise: playing basketball, running, or jogging \\
\hline
\end{tabular}

${ }^{\mathrm{a}}$ These variables were summed to derive a heat adaptation level ranging from 0 to 6 .

$$
\begin{aligned}
\mathrm{HI}= & -42.379+2.04901523 T+10.14333127 R \\
& -0.22475541 T R-6.83783 \times 10^{-3} T^{2} \\
& -5.481717 \times 10^{-2} R^{2}+1.22874 \times 10^{-3} T^{2} R \\
& +8.5282 \times 10^{-4} T R^{2}-1.99 \times 10^{-6} T^{2} R^{2}
\end{aligned}
$$

where $T=$ dry-bulb temperature $\left({ }^{\circ} \mathrm{F}\right)$ and $R=$ relative humidity (\%). For this equation, dry-bulb temperatures were converted from degree Celsius to Fahrenheit. Relative humidity was obtained from wet- and dry-bulb measurements using a psychrometric chart as provided by the manufacturer, which employs the set of psychrometric equations provide by, for example, Snyder and Snow (1984).

From the heat index that was calculated using the daily maximum temperatures measured at the investigation site, we categorized the 12 investigation days into three weather categories. According to the German Meteorological Service (Deutscher Wetterdienst 2020b,c), a day with a maximum temperature $\geq 25^{\circ} \mathrm{C}$ is a summer day and a day with a maximum temperature $\geq 30^{\circ} \mathrm{C}$ is a hot day. In addition to these two categories, we defined days with $\mathrm{HI}<25^{\circ} \mathrm{C}$ and rain during the observation and survey period as rainy days.

\section{3) FACE-TO-FACE SURVEY}

The on-site surveys were conducted between 1500 and 1800 local time on every study day. Visitors were approached at the two main entrances (Fig. 1) when leaving the exhibition grounds. The faceto-face surveys were carried out with a standardized questionnaire. Table 3 shows the questions and answer options used in this study.

We asked the visitors where they looked for weather information, what knowledge they had of current weather warnings, what their subjective perceptions were of the weather condition at the event site, and whether they perceived the weather as a burden or limitation on their activities. Heat risk awareness was measured by a three-item scale (see Table 3). Next, we addressed measures of individual heat adaptation and asked respondents to evaluate how helpful given measures were in coping with hot weather conditions, which we related to the perceived response efficacy of private adaptation measures described below. Subsequently, we asked the visitors about their actual behavior using the same behavioral categories (adaptive behavior). In the following, the respondents evaluated the preparedness of the event organizers and the responsibility to take adaptation measures to counteract heat stress of both the organizers and themselves as visitors. The visitors were also asked about their age.

\section{c. Sample}

Samples for the behavioral observations and the surveys were collected independently from each other. Nevertheless, it must be mentioned that both samples may intersect.

\section{1) BEHAVIORAL OBSERVATIONS}

Overall, 2750 visitors were observed, of which $56.7 \%$ were female $(n=1559)$ and $43.0 \%$ were male $(n=1182)$. Nine very young visitors $(0.3 \%)$ could not be categorized clearly by the observers. The most frequently observed age groups were " $31-60$ " with a total of $41.2 \%(n=1129)$ and "above 60 " with a total of $28.5 \%(n=782)$.

\section{2) FACE-TO-FACE SURVEYS}

In total, 306 visitors were surveyed; $186(60.8 \%)$ of the respondents were female, and $111(36.3 \%)$ were male. Nine survey interviews $(2.9 \%)$ were conducted with groups of two or more people and thus no information on gender was provided. The age of the respondents who indicated their exact age ranged from 11 to 85 (mean $M=53.8$; standard deviation $\mathrm{SD}=15.7$; number

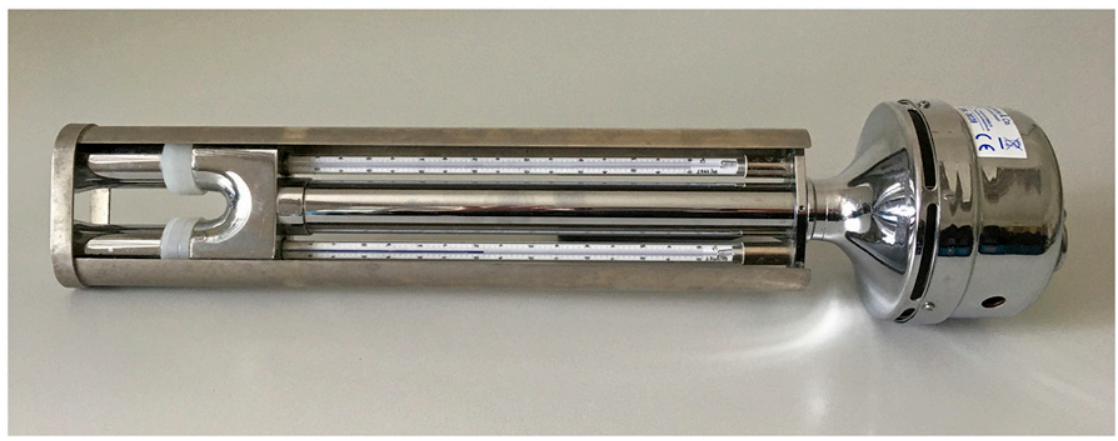

FIG. 2. Assmann aspiration-type psychrometer (photograph: A. Bauer). 
TABLE 3. Questions on heat risk awareness and adaptation with answer options.

\begin{tabular}{|c|c|c|}
\hline Construct & Question & Answer options \\
\hline $\begin{array}{l}\text { Weather information } \\
\text { search }\end{array}$ & $\begin{array}{l}\text { Where or how did you inform yourself about the weather forecast before } \\
\text { your visit? }\end{array}$ & Open \\
\hline $\begin{array}{l}\text { Knowledge about weather } \\
\text { warning }\end{array}$ & Was there an official warning given today, to your knowledge? & Yes/no; if yes: open answer \\
\hline Weather perception & How would you describe the weather at the event site today? & Open \\
\hline Burdened by weather & Did you feel burdened by the weather conditions today? & $\begin{array}{l}1=\text { not burdened }-5=\text { severely } \\
\text { burdened }\end{array}$ \\
\hline $\begin{array}{l}\text { Limited in activities by } \\
\text { weather }\end{array}$ & $\begin{array}{l}\text { Did you feel limited in your activities by the weather conditions today? } \\
\text { (Could you, for example, not carry out all of your intended actions?) }\end{array}$ & $\begin{array}{l}1=\text { not limited }-5=\text { strongly } \\
\text { limited }\end{array}$ \\
\hline Heat risk awareness & $\begin{array}{l}\text { Please answer how much you agree with the following statements: 1) heat } \\
\text { can have serious consequences for health, 2) it is important to adapt } \\
\text { one's behavior on hot days, and 3) heat is not a serious danger } \\
\text { (inverted item) }\end{array}$ & $1=$ do not agree $-5=$ fully agree \\
\hline $\begin{array}{l}\text { Private adaptation } \\
\text { measures }\end{array}$ & $\begin{array}{l}\text { What do you think, how can everyone personally adapt to hot } \\
\text { temperatures? }\end{array}$ & Open \\
\hline $\begin{array}{l}\text { Perceived response } \\
\text { efficacy }\end{array}$ & $\begin{array}{l}\text { How helpful do you find the following measures in coping with hot days? } \\
\text { 1) drinking more, 2) wearing light clothing, 3) wearing a head covering, } \\
\text { 4) avoiding bodily strain, 5) staying in the shade and avoiding direct } \\
\text { sunlight, and 6) changing time management }\end{array}$ & $\begin{array}{l}1=\text { not at all helpful-5 = very } \\
\text { helpful }\end{array}$ \\
\hline Adaptive behavior & $\begin{array}{l}\text { Did you ... today? 1) deliberately drink more, 2) wear light clothing, 3) } \\
\text { wear a head covering, 4) avoid bodily strain, 5) deliberately stay in the } \\
\text { shade and avoid direct sunlight, and/or 6) plan your day differently }\end{array}$ & Yes/no \\
\hline $\begin{array}{l}\text { Precautionary measures } \\
\text { (public) }\end{array}$ & $\begin{array}{l}\text { Did you notice measures that the organizers had taken to protect visitors } \\
\text { from heat stress at the event site? }\end{array}$ & Open \\
\hline Preparedness & In my view, the Landesgartenschau is ... & $\begin{array}{l}1=\text { not at all prepared }-5=\text { very } \\
\text { well prepared for heat stress }\end{array}$ \\
\hline Responsibility & $\begin{array}{l}\text { Who is, in your opinion, responsible for mitigating the negative impacts of } \\
\text { heat stress during your visit? 1) the Landesgartenschau, and 2) I am }\end{array}$ & $\begin{array}{l}1=\text { not at all responsible }-5= \\
\text { very strongly responsible }\end{array}$ \\
\hline
\end{tabular}

$n=265$ ): $0.7 \%$ were 18 years old or younger, $11.1 \%$ were between 19 and 31 years old, $52.3 \%$ were between 31 and 60 years old, and the remaining $35.9 \%$ were older than 60.249 respondents lived in Bavaria $(81.3 \%)$, of which $72(23.5 \%)$ lived in Würzburg and $35(11.4 \%)$ in the areas directly surrounding Würzburg.

\section{d. Statistical analyses}

The analyses are divided into two sections: first, we investigate different aspects of heat risk appraisal; second, the self-reported and observed adaptive behavior is described. Since many adaptation measures are not useful during rainy weather (e.g., light clothing, staying in the shade, or drinking more), we usually excluded the two rainy days from the following analyses.

All statistical analyses were conducted with IBM Statistical Product and Service Solutions (SPSS), version 27. Descriptive analyses are reported. Bivariate correlation analyses were calculated to test interdependencies between variables. To compare manifestations of heat risk perception and adaptive behavior across the three above-named weather categories and between different age groups, univariate ANOVA, two-way ANOVA, and regression analyses were calculated. All effect sizes were interpreted according to Cohen (1988).

\section{Results}

Research was conducted on six consecutive weekends in July and August 2018. Of the 12 investigation days, $n=3$ were categorized as hot days ( $\left.\mathrm{HI} \geq 30^{\circ} \mathrm{C}\right), n=7$ were categorized as summer days $\left(\mathrm{HI} \geq 25^{\circ} \mathrm{C}\right)$, and $n=2$ were categorized as rainy days $\left(\mathrm{HI}<25^{\circ} \mathrm{C}\right.$ and rain during the observation and survey period; see Fig. 3). The official number of visitors was recorded by the event organizers and categorized as holding either daily or season tickets. Next to these overview data, the total number of observations and surveys per day are provided in Fig. 3.

Across the 12 investigation days, the event had on average $M=5136$ (SD = 1654) visitors per day. In total, these numbers did not vary significantly among the three weather categories (hot, summer, and rainy). However, the visitor numbers were divided between daily and season ticket holders (Fig. 3). During the seven summer days, the highest average number of visitors with season tickets was recorded $(M=1770.5 ; \mathrm{SD}=624.6)$, which was more than 2 times the average during hot days $(M=711.7$; $\mathrm{SD}=$ 191.2 ), with $t(8)=2.79, p=0.023$, and $d=1.98$. Many people with daily tickets had probably planned their trip (possibly with a tour operator) to the Landesgartenschau long in advance and therefore could not change their plans spontaneously according to the daily weather forecast. A season ticket offered visitors the opportunity to visit the event grounds as often as they wished during the 6-month event period, which was attractive especially for local residents and offers a lot of flexibility with regard to the weather conditions.

\section{a. Weather and heat risk appraisal}

Most respondents $(70.9 \%)$ stated that they had informed themselves about the weather forecast before their visit. They 


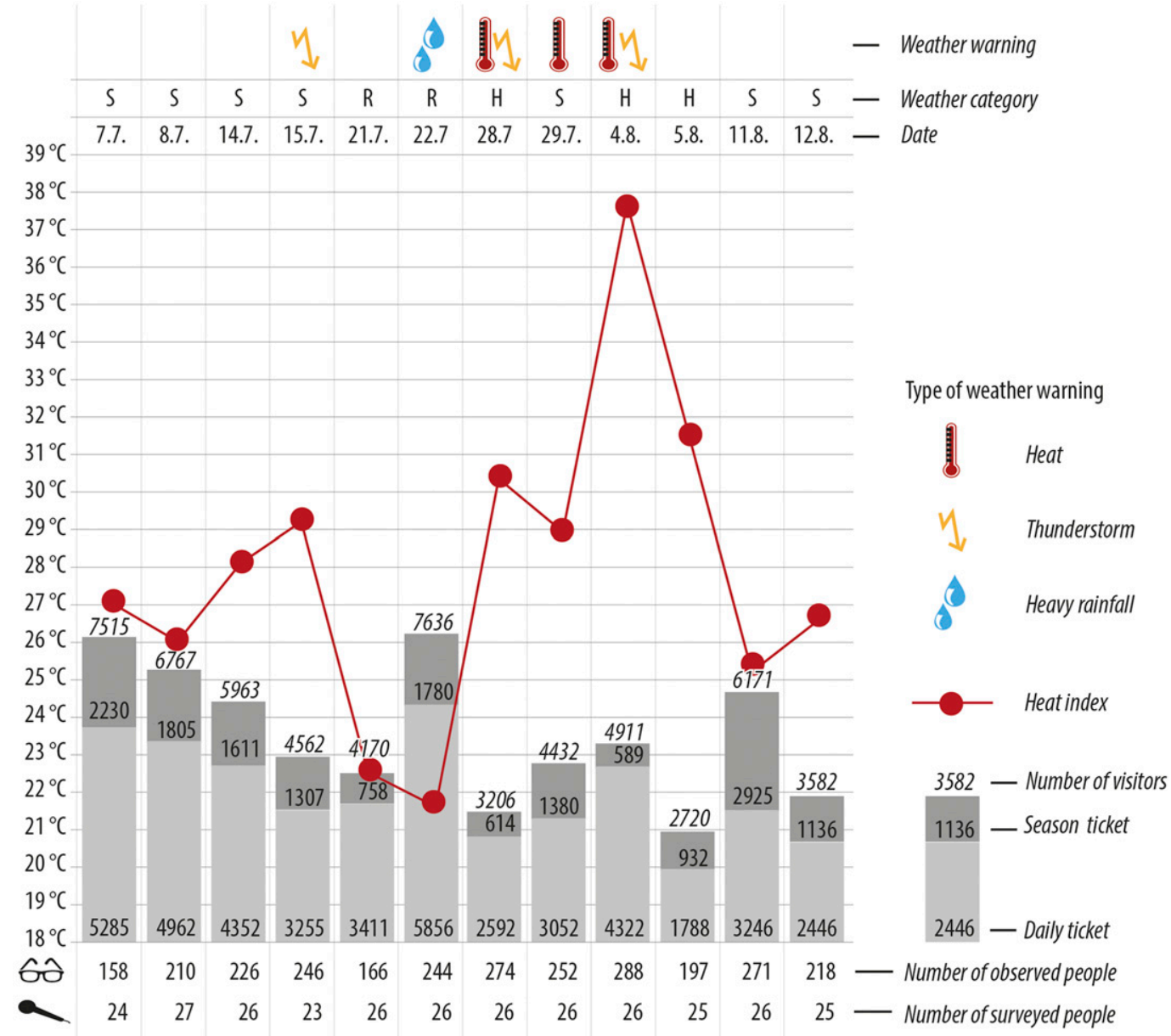

FIG. 3. Overview of all 12 observation days: official weather warnings, weather category (H: hot, S: summer, or R: rainy day), heat index $\left({ }^{\circ} \mathrm{C}\right)$, number of visitors per ticket category, number of observed people, and number of surveyed people.

referred to weather applications ("apps"; $28.4 \%$ ), the Internet $(26.1 \%)$, television $(13.4 \%)$, the radio $(8.8 \%)$, a mere look out of the window $(8.2 \%)$, and newspapers $(3.3 \%)$ as their main sources of information.

On three observation days, the DWD had issued an official heat warning (see Fig. 3). Asked if they knew about the official weather warning, only $10 \%$ ( $n=8$ of 78 people surveyed on these three days) replied that they had heard the heat warning; $90 \%(n=70)$ replied that to their knowledge there was no weather warning at all or the warning was not applicable, such as for thunderstorms, heavy rainfall, or ozone. Thunderstorm warnings, which were also issued on three observation days (see Fig. 3), were better known: $16 \%(n=12)$ of the $n=75$ respondents on these days recalled this warning. The heavy rainfall warning, which was issued on one day, was known to none of the $n=26$ respondents. We examined whether people from different age groups gave different answers to the warning question but found no significant effect in either direction. No age group stood out with either particularly high or particularly low knowledge about warnings, and falsely attributed weather warnings were evenly distributed, too.
Depending on the weather type, the respondents reported different weather perceptions. The answers were categorized as follows: the three hot days $(n=77)$ were described as hot $(52 \%)$, positive (40\%), warm (20\%), windy (20\%), sultry (12\%), negative $(10 \%)$, sunny $(8 \%)$, summer weather $(5 \%)$, changeable $(3 \%)$, and oppressive $(1 \%)$. The respondents perceived the weather on the seven summer days $(n=177)$ as mostly positive $(50 \%)$, hot $(32 \%)$, warm $(28 \%)$, windy $(21 \%)$, sultry $(10 \%)$, sunny $(9 \%)$, negative, oppressive, unsettled/changeable (each 6\%), summer weather $(5 \%)$, and fresh $(1 \%)$. On both rainy days $(n=52)$, the weather was described as positive $(37 \%)$, negative $(19 \%)$, sultry (14\%), oppressing $(10 \%)$, unsettled/changeable (8\%), windy $(6 \%)$, fresh (4\%), warm, cold, and sunny (each $2 \%)$. The category "positive" includes terms such as "good," "nice," and "beautiful," whereas the category "negative" comprises words like "bad," "horrible," and occasionally swear words. An ANOVA reveals that the percentage of respondents describing the day negatively varies significantly across the day types: $F(2,303)=4.648, p=$ 0.010 , and $\eta^{2}=0.030$. Pairwise comparisons show that this difference is significant between summer and rainy days. Older visitors tended to describe the weather conditions more positively, as 


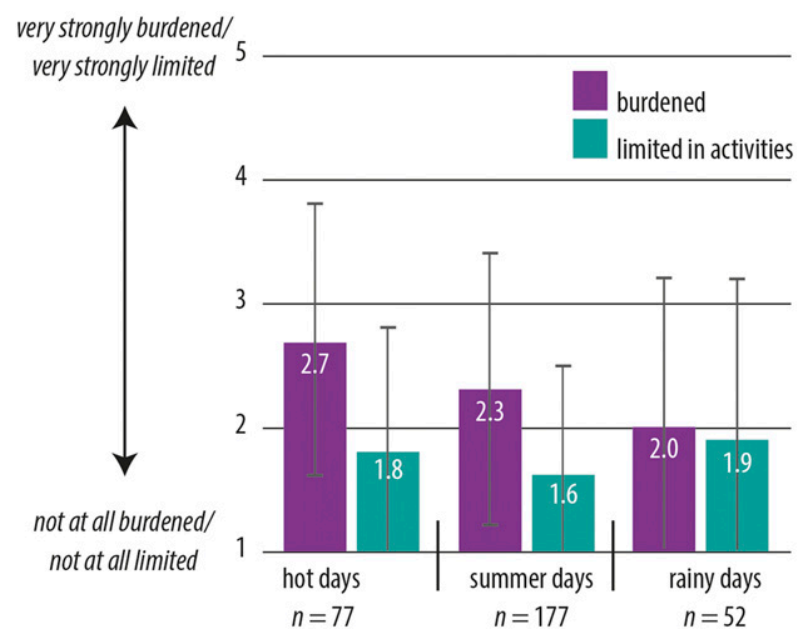

FIG. 4. Levels of burden and limitation by weather expressed on hot, summer, and rainy days (means and standard deviations).

bivariate correlation analysis shows, correlation coefficient $r=$ 0.135 , with $p=0.029$. There was no significant correlation between age and negative weather perceptions.

Across all observation days, the respondents reported an average level of $2.3(\mathrm{SD}=1.1)$ to reflect the feeling of being burdened by the weather and an average level of $1.7(\mathrm{SD}=1.0)$ with regard to limitation in activities. Both scales correlated: $r=0.499$, with $p<0.001$. On hot days, the respondents felt more burdened by the weather than they did on summer days and rainy days (Fig. 4). This difference between the weather categories was significant, as an ANOVA revealed: $F(2,303)=$ 5.945, $p=0.003$, and $\eta^{2}=0.038$. Pairwise comparisons showed that hot days differed significantly from rainy days. Asked to what extent they felt limited in their activities by the weather, respondents reported a lower level during summer days relative to those interviewed during hot and rainy days (Fig. 4), however, this effect showed only a weak significance: $F(2,303)=2.543, p=0.080$, and $\eta^{2}=0.017$. Between the different age groups, no significant differences in perceived burden or limitation were observed.

For the three items measuring heat risk perception (see Table 3), a normal distribution was not given. Most respondents expressed a high level of approval $(M=4.6$; $\mathrm{SD}=0.6)$, indicating a high level of heat risk awareness. The three-item scale did not show a satisfactory reliability according to Cronbach's alpha $(\alpha=0.517)$. The answers did not differ significantly between age groups, nor between weather categories.

The majority of the respondents (62\%) stated that they had noticed heat adaptation measures taken by the organizers at the event site. The most frequently named measures were parasols, shade-providing trees, awnings, sprinklers, a small train that transported visitors between different sights at the scene, the water dispenser, and the water basin.

On average, the respondents regarded the event's organizers as showing medium-level preparedness for preventing heat stress $(M=3.0$ and SD $=0.9$, rated on a scale from $1=$ not at all prepared to $5=$ very well prepared). Perceived preparedness of the organizers showed small negative correlations with burden $(r=-0.122$, with $p=0.032)$ and limitation $(r=-0.160$, with

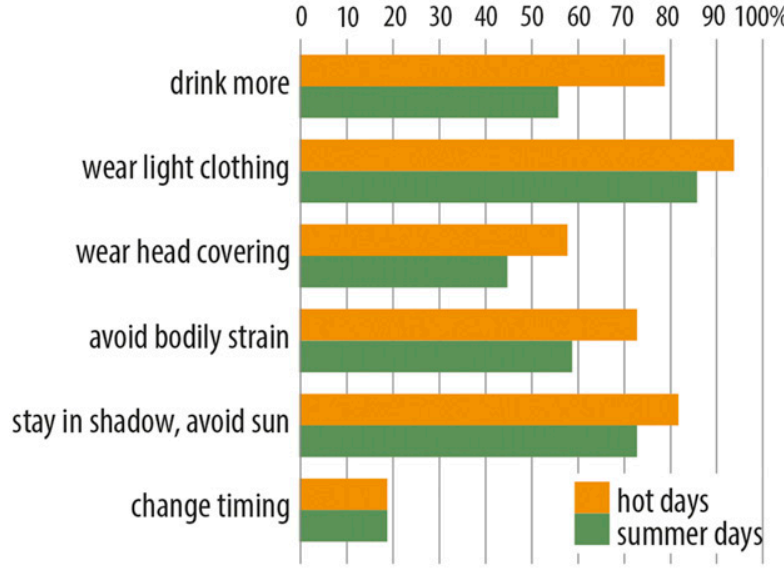

FIG. 5. Percentage of respondents who reported having carried out specific adaptation measures depending on weather category (hot day: $n=77$; summer day: $n=177$ ).

$p=0.005)$, indicating that those who felt a higher negative impact of the weather conditions esteemed the organizers to be less prepared than visitors who felt less impaired by the heat.

The respondents perceived the organizers to be moderately responsible for protecting visitors against the consequences of heat stress $(M=3.0 ; \mathrm{SD}=1.2)$. Their perceived individual responsibility was high $(M=4.4 ; \mathrm{SD}=0.9)$. Both values correlated negatively on a low level: $r=-0.149$, with $p<0.001$, which means that people with a higher reported level of individual responsibility perceived the organizers to be less responsible, and vice versa. Results on subjective preparedness and responsibility did not differ significantly between the weather conditions.

\section{b. Heat-adaptive behavior}

\section{1) SELF-REPORTED ADAPTIVE BEHAVIOR}

Most surveyed visitors rated all six presented measures (see Table 3) as very helpful in coping with hot days (overall $M=$ 4.6; SD $=0.4$ ), which did not differ significantly between summer and hot days (or rainy days).

During hot days, the visitors reported having carried out more adaptation measures (Fig. 5). On average, $M=4.0(\mathrm{SD}=1.1)$ of the six queried adaptation measures were carried out. A multiple regression on the number of self-reported adaptation

TABLE 4. Multiple regression on the additive influence of various factors on the self-reported number of applied adaptation measures to heat stress.

\begin{tabular}{lrcrrr}
\hline \hline & $B$ & $\mathrm{SE}(B)$ & \multicolumn{1}{c}{$\beta$} & \multicolumn{1}{c}{$T$} & \multicolumn{1}{c}{$p$} \\
\hline Hot day & 0.89 & 0.19 & 0.28 & 4.80 & $<0.001$ \\
Burden & 0.22 & 0.08 & 0.17 & 2.64 & 0.009 \\
Limitation & 0.11 & 0.09 & 0.07 & 1.15 & 0.250 \\
$\begin{array}{l}\text { Responsibility of } \\
\quad \text { organizers }\end{array}$ & -0.13 & 0.07 & -0.11 & -1.88 & 0.062 \\
Responsibility of myself & 0.18 & 0.09 & 0.12 & 2.08 & 0.038 \\
Age & 0.01 & 0.01 & 0.14 & 2.47 & 0.014 \\
\multicolumn{1}{c}{$R^{2}=0.200, p<0.001$, and $n=265$} & & \\
\hline
\end{tabular}



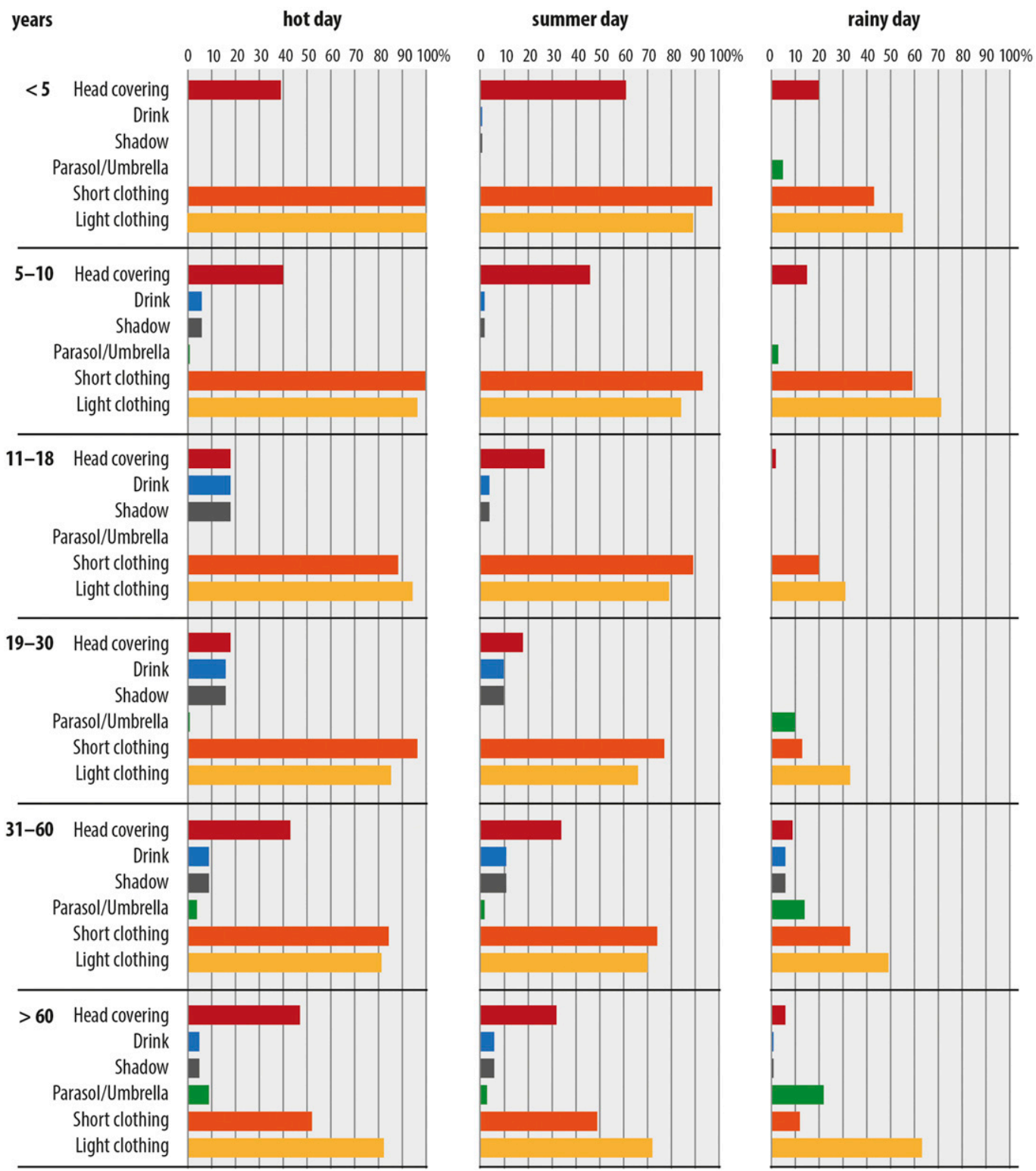

FIG. 6. Observed weather adaptation measures per age group and weather category. The bars depict the percentage of each age group that had carried out the respective adaptation measure.

measures revealed a number of significant factors (Table 4). During hot days, when feeling more burdened by the weather and responsible for protecting themselves against heat stress, people reported carrying out more adaptation measures. Furthermore, older people reported adopting more adaptation measures (Table 4). The feeling of being limited by the weather and a higher perception of the organizers' responsibility to carry out adaptation measures did not have a significant impact on self-reported adaptive behavior (Table 4).

\section{2) OBSERVED BEHAVIOR}

Across the different weather categories, the observed visitors showed a variety of adaptation measures to the weather conditions, which seems to also be influenced by age (Fig. 6 and Table 5). During hot days, the average number of observed adaptation measures per observed visitor was $M=2.4(\mathrm{SD}=0.9)$, whereas it was $M=2.1(\mathrm{SD}=1.0)$ on summer days and $M=1.0(\mathrm{SD}=0.9)$ on rainy days (Table 4). A two-way ANOVA of age group and weather category shows a significant main effect of the weather category on the number of observed adaptation measures: $F(2,2723)=207.987, p<0.001$, and partial $\eta^{2}=0.133$, which can be regarded as a large effect. Further, there is also a significant main effect of the age group: $F(5,2723)=$ $12.150, p<0.001$, and partial $\eta^{2}=0.022$. The interaction effect of weather category and age group is $F(10,2723)=2.867$, 
TABLE 5. Mean $(M)$ number of observed measures, standard deviations (SD), and the number of people $(n)$ in each age group per weather category.

\begin{tabular}{|c|c|c|c|c|c|c|c|c|c|}
\hline \multirow[b]{2}{*}{ Age group } & \multicolumn{3}{|c|}{ Hot day } & \multicolumn{3}{|c|}{ Summer day } & \multicolumn{3}{|c|}{ Rainy day } \\
\hline & $M$ & SD & $n$ & $M$ & SD & $n$ & $M$ & SD & $n$ \\
\hline$<5$ & 2.6 & 0.6 & 28 & 2.6 & 0.8 & 124 & 1.2 & 1.0 & 57 \\
\hline $5-10$ & 2.7 & 0.8 & 67 & 2.4 & 0.8 & 90 & 1.5 & 0.9 & 56 \\
\hline 11-18 & 2.3 & 0.8 & 17 & 2.2 & 1.0 & 71 & 0.5 & 0.7 & 40 \\
\hline 19-30 & 2.4 & 0.8 & 82 & 2.0 & 1.1 & 193 & 0.6 & 0.6 & 108 \\
\hline $31-60$ & 2.4 & 0.9 & 320 & 2.1 & 1.0 & 671 & 1.1 & 1.0 & 340 \\
\hline$>60$ & 2.2 & 1.0 & 243 & 1.8 & 1.0 & 426 & 1.0 & 0.9 & 251 \\
\hline Total & 2.4 & 0.9 & 757 & 2.1 & 1.0 & 1575 & 1.0 & 0.9 & 852 \\
\hline
\end{tabular}

$p=0.001$, and partial $\eta^{2}=0.010$. Both effect sizes may be considered small.

During the investigation days, the observed visitors carried out a variety of different activities (Table 2), as can be seen in Fig. 7. During hot days, the average activity level across all observed visitors was $M=0.8(\mathrm{SD}=0.7)$, whereas it was $M=$ $0.7(\mathrm{SD}=0.7)$ on summer days and $M=0.9(\mathrm{SD}=0.8)$ on rainy days (Table 6). A two-factorial ANOVA of age group and weather category on the level of activity revealed a significant main effect of the age group: $F(5,2720)=32.975, p<$ 0.001 , and partial $\eta^{2}=0.057$, and a significant main effect of the weather category: $F(2,2720)=3.322, p=0.036$, and partial $\eta^{2}=0.002$. Based on the medium effect size of the age group, we conclude that the level of activity differed more between age groups than it does between hot and summer days. Pairwise comparisons showed that the three youngest age groups each differed significantly from the three oldest age groups (see Fig. 7 for descriptive results on means and standard deviations for each age group in both weather categories).

\section{Discussion}

This study explored the impact of heat stress on visitors to open-air events comparing behavior at four locations with different environmental states between three weather categories. Effects were both observed by the researchers and self-reported by the visitors. The combination of methods we used in this multimethod approach resulted in a number of noteworthy findings that are a new contribution to scientific research.

The official DWD heat warnings were not known to the vast majority of respondents, which seems to contradict reports on the general high awareness of heat warnings in Germany (Capellaro et al. 2015). Our results on weather and heat risk appraisal point to a generally lack of heat risk awareness among visitors to the open-air event. One possible reason for the relatively low number of visitors during hot days is that people aware of heat warnings might have decided against a visit and thus could not be surveyed (but adapted to the weather conditions). Apart from knowledge about heat warnings, a high level of awareness on the topic of heat stress in general was reported. However, it has to be kept in mind that the topic of heat (stress) was salient after the first few questions and thus social desirability was possibly one factor that led to very high levels of agreement on the heat awareness items.
Nevertheless, the existing ignorance of warnings among visitors should be taken seriously. We see a need in further research on the effectiveness of heat warning systems as also requested by Toloo et al. (2013).

On hot days, the surveyed respondents reported experiencing a higher level of burden from the weather condition than those on summer or rainy days. This did not differ between age groups, which was a surprising finding since the elderly are regarded as a more vulnerable group with respect to heat. Some studies state the negative impact of heat stress beyond vulnerable groups (KunzPlapp et al. 2016). In future surveys, it would be advisable to assess impacts on well-being and health using a more detailed scale. The question of subjective limitation due to the weather condition rather reflects a personal annoyance about the weather and less a health-relevant stress appraisal. Consequently, respondents indicated an increased level of perceived limitation on both hot and rainy days, because both weather conditions logically may hinder one in pursuing outdoor activities. The on-site paramedics team did not report higher case numbers during hotter days (T. Witzel, Johanniter-Unfallhilfe e.V. Würzburg 2018, personal communication); thus, no negative health impacts could be observed during the Landesgartenschau directly.

The surveyed visitors showed a broad agreement about the helpfulness of private adaptation measures to heat stress. Nevertheless, they reported having carried out only some of these measures. This is in line with the large body of literature on what is known as the attitude-behavior gap, which describes how a motivation or intention does not necessarily lead to the intended behavior, be it health behavior (Orbell and Sheeran 1998) or ethical consumerism (Kollmuss and Agyeman 2002). During the observations, we noted that the shaded seating accommodations were scarcely used by the elderly with physical handicaps, because they often were installed at low height. To foster individual adaptation, easily accessible shaded seating areas should be provided. Older visitors reported taking a higher level of adaptation measures (Fig. 4); however, we observed an increased adaptation level in the youngest age groups (Fig. 6). One possible explanation lies in the standardized protocol, which did not allow for differentiation between age-typical adaptation measures. Older people usually do not wear short clothing but tended in our study to wear light clothing and head coverings. In future observations on heat adaptation behavior, age, gender, religion, and other possible group differences should be heeded in the design of the research materials. Nevertheless, the impediments to adaptation discussed above can be regarded as an obstacle to adaptive behavior for the elderly.

The recorded visitor numbers indicate that people avoided visiting the event during hot days using the flexibility offered by their season ticket. This can be regarded as a very basic adaptation measure initiated by heat risk awareness (Sharifi and Boland 2018). Thus, the presented data are biased: people who decided to avoid the event could be neither observed nor surveyed. Household surveys can help to shed light on a broader population's perceptions and the drivers of their actions.

Visitors who reported higher levels of burden and impairment stated that they carried out more adaptation measures (Table 4). People who have personally experienced heat-related negative 


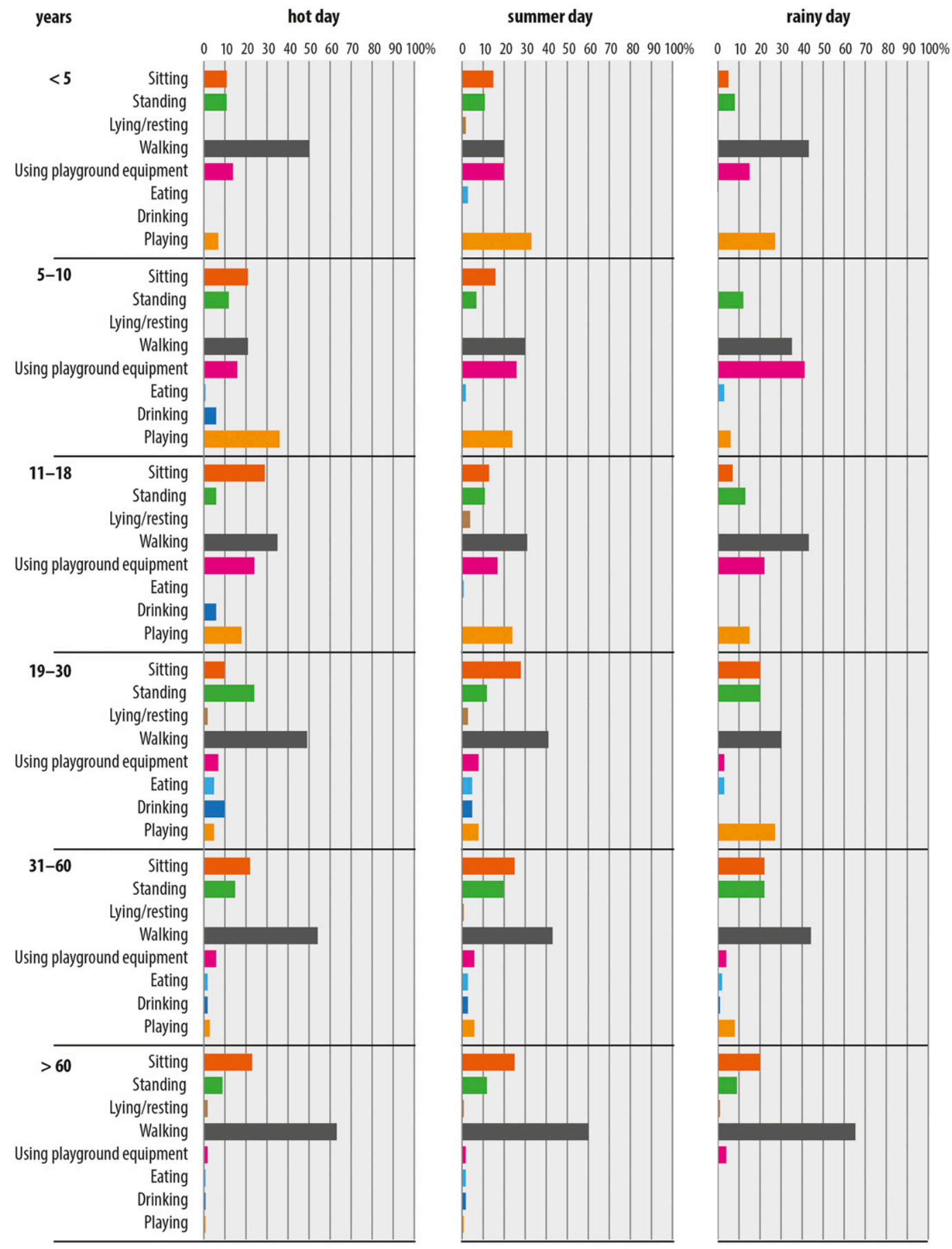

FIG. 7. Observed activities per age group and weather category. The bars depict the percentage of each age group that had carried out the respective activity.

health impacts before are prone to showing more adaptive behavior, according to recent research (Esplin et al. 2019). Our study indicates that the personal experience of impairments to well-being can have an immediate effect on adaptive behavior.

For the activity level, age had a bigger impact than weather: older people generally showed a lower level of activity, whereas children and younger adults were rather active during all observation days. Taking things slow on a hot day can be regarded as a measure of heat stress adaptation, which tends to be taken by elder people (i.e., people aged 60 years and over). Children showed consistently higher levels of activity during all weather conditions (Fig. 7), which should be considered when 
TABLE 6. Similar to Table 5, but for level of activity on a scale from $0=$ calm activity to $3=$ strong physical exercise.

\begin{tabular}{|c|c|c|c|c|c|c|c|c|c|}
\hline \multirow[b]{2}{*}{ Age group } & \multicolumn{3}{|c|}{ Hot day } & \multicolumn{3}{|c|}{ Summer day } & \multicolumn{3}{|c|}{ Rainy day } \\
\hline & $M$ & SD & $n$ & $M$ & SD & $n$ & $M$ & SD & $n$ \\
\hline$<5$ & 1.0 & 0.8 & 28 & 1.0 & 0.8 & 123 & 1.1 & 0.6 & 40 \\
\hline $5-10$ & 1.4 & 1.2 & 67 & 1.2 & 0.9 & 88 & 1.4 & 0.8 & 34 \\
\hline $11-18$ & 0.9 & 0.8 & 17 & 1.1 & 1.0 & 71 & 1.2 & 0.8 & 54 \\
\hline $19-30$ & 0.7 & 0.7 & 82 & 0.7 & 0.8 & 193 & 1.0 & 1.1 & 30 \\
\hline $31-60$ & 0.7 & 0.6 & 320 & 0.6 & 0.7 & 671 & 0.7 & 0.7 & 138 \\
\hline$>60$ & 0.7 & 0.5 & 243 & 0.6 & 0.5 & 426 & 0.7 & 0.5 & 113 \\
\hline Total & 0.8 & 0.7 & 757 & 0.7 & 0.7 & 1572 & 0.9 & 0.8 & 409 \\
\hline
\end{tabular}

planning for event sites to be safely accessible during different kinds of weather.

The high level of perceived self-responsibility expresses a general willingness on the part of visitors to carry out adaptive behavior. Most people feel very responsible for protecting themselves from negative impacts of heat stress, but they also regard the organizers as being responsible for offering protection. Authorities and event organizers have to take this responsibility seriously and offer the adaptation aids discussed above and communicate warnings and risks together with suitable adaptive behavior at the event site.

\section{a. Limitations}

One advantage of the applied multimethod approach is the attenuation of weaknesses of the different methods used. Through the balanced use of quantitative observation and survey methods, we explored risk perception factors, self-reported behavior, and observable behavior, partly compensating for gaps that could not be explained by either method alone. Relying on self-reported information alone brings along the risk of social desirability in respondents' answers; the observation of actual behavior, however, does not allow for statements revealing people's thoughts and perceptions. Taken together, a complete compensation of the pitfalls of either method is not guaranteed, but a broader picture of visitors' heat risk perception and behavior can be provided.

\section{b. Policy implications}

We recommend that organizers and authorities communicate official warnings more widely, for example, at the entrances, on their website, and to tour operators, and to combine such warnings with a recommendation on individual adaptation measures. Advice on implementing heat risk communication and HHWS is given in recent literature (Grothmann et al.2017). Tailored communication strategies are recommended so as to equally reach all members of heterogeneous audiences (Mayrhuber et al. 2018).

To increase adaptive behavior in visitors, adaptation measures should be facilitated for all groups. Therefore, it is recommendable to offer aids, such as drinking fountains, shade, and adequate seating areas at open-air events, but also in public spaces, such as city centers. Organizers of future events should pay attention to children's needs for play opportunities (in the water) and offer shading and cooling wherever possible. Water play areas and awnings can increase an event's popularity among children and their parents, which lies in the economic interests of event organizers. However, water installations bring with them further challenges in the form of financial, maintenance, and hygienic aspects.

\section{Conclusions}

In the past 10 years, we have experienced the hottest summers recorded in Germany to date. In the future heat waves are likely to occur more often, last longer and be more intense (Pachauri et al. 2014; Field et al. 2012; Fischer and Schär 2010). They pose a serious health threat, especially to vulnerable groups. This study gives insights into visitor behavior at an open-air event during hotter and milder periods. We discovered age related differences in heat risk perception and adaptive behavior. Behavioral observations and face-to-face surveys proved to be helpful methods and will, it is hoped, be carried out more frequently in future research on heat perception and adaptation. Extending observation and survey protocols by integrating qualitative methods and focusing on different target groups will increase our understanding of heat risk perception and adaptation of heterogeneous audiences.

Even though heat is often acknowledged as an abstract problem, the personal relevance of the hazard is not known by all people, and thus simple adaptation measures may not be heeded. A focus needs to be set on communication: both the long-term risk communication about health problems that heat stress can cause for humans, as well as the short-term crisis communication through warnings, weather information, and behavior recommendations. By using tailored communication methods, different groups of people can be reached and informed. Organizers and authorities have to heed the heterogeneity of their visitors and citizens: individual adaptive behavior needs to be easily achievable for people of all ages and regardless of their state of health.

Acknowledgments. This research was conducted as part of the research project "Urban resilience against extreme weather events-Typologies and transfer of adaptation strategies in small metropolises and medium-sized cities" (ExTrass) funded by Germany's Federal Ministry of Education and Research (BMBF, FKZ 01LR1709A, and 01LR1709A1). We are grateful for the Landesgartenschau Würzburg organizers who supported our research. We thank Sophia Kiefl for her contribution to the data collection and the Johanniter Unfallhilfe e. V. for providing data.

Data availability statement. Because of privacy and ethical concerns, neither the data from the behavioral observations nor the survey data can be made available.

\section{REFERENCES}

Abrahamson, V., J. Wolf, I. Lorenzoni, B. Fenn, S. Kovats, P. Wilkinson, W. N. Adger, and R. Raine, 2009: Perceptions of heatwave risks to health: Interview-based study of older people in London and Norwich, UK. J. Public Health, 31, 119-126, https://doi.org/10.1093/pubmed/fdn102.

Akompab, D. A., P. Bi, S. Williams, J. Grant, I. A. Walker, and M. Augoustinos, 2013: Heat waves and climate change: Applying the health belief model to identify predictors of risk 
perception and adaptive behaviours in Adelaide, Australia. Int. J. Environ. Res. Public Health, 10, 2164-2184, https://doi.org/ 10.3390/ijerph10062164.

Anderson, C. A., 2016: Heat and violence. Curr. Dir. Psychol. Sci., 10, 33-38, https://doi.org/10.1111/1467-8721.00109.

Bittner, M.-I., and U. Stößel, 2012: Perceptions of heatwave risks to health: Results of an qualitative interview study with older people and their carers in Freiburg, Germany. GMS PsychoSoc. Med., 9, 5, https://doi.org/10.3205/psm000083.

Borg, M. A., and Coauthors, 2021: Occupational heat stress and economic burden: A review of global evidence. Environ. Res., 195, 110781, https://doi.org/10.1016/j.envres.2021.110781.

Breakwell, G. M., 2014: The Psychology of Risk. Cambridge University Press, 384 pp.

Burke, M., F. González, P. Baylis, S. Heft-Neal, C. Baysan, S. Basu, and S. Hsiang, 2018: Higher temperatures increase suicide rates in the United States and Mexico. Nat. Climate Change, $\mathbf{8}$, 723-729, https://doi.org/10.1038/s41558-018-0222-x.

Capellaro, M., D. Sturm, P. Sadre Dadras, P. Kahn, and D. Briggs, 2015: Adaption to climate change: Evaluation of existing national information systems (UV-index, heat warning system, airborne pollen and ozone forecasts) from a public health perspective- - how to reach vulnerable populations. Vol. 1, Evaluation of information systems relevant to climate change and health, Umwelt \& Gesundheit, Federal Ministry for the Environment, Nature Conservation, Building and Nuclear Safety Rep. (UBA-FB) 002979/E, 138 pp., https://www.umweltbundesamt.de/sites/ default/files/medien/378/publikationen/ug_07_2015_evaluation_ of_information_systems_volume_1_0.pdf.

Cedeño Laurent, J. G., A. Williams, Y. Oulhote, A. Zanobetti, J. G. Allen, and J. D. Spengler, 2018: Reduced cognitive function during a heat wave among residents of non-airconditioned buildings. PLOS Med., 15, e1002605, https:// doi.org/10.1371/journal.pmed.1002605.

Centre for Research on the Epidemiology of Disasters, 2021: 2020: The non-COVID year in disasters. CRED and UNDRR Publ., 8 pp., https://www.undrr.org/publication/2020-non-covid-yeardisasters.

Cohen, J., 1988: Statistical Power Analysis for the Behavioral Sciences. Erlbaum, 567 pp.

Coumou, D., and S. Rahmstorf, 2012: A decade of weather extremes. Nat. Climate Change, 2, 491-496, https://doi.org/ 10.1038/nclimate1452.

Dalelane, C., and T. Deutschländer, 2013: A robust estimator for the intensity of the Poisson point process of extreme weather events. Wea. Climate Extremes, 1, 69-76, https://doi.org/ 10.1016/j.wace.2013.07.003.

de Freitas, C. R., and E. A. Grigorieva, 2017: A comparison and appraisal of a comprehensive range of human thermal climate indices. Int. J. Biometeor., 61, 487-512, https://doi.org/10.1007/ s00484-016-1228-6.

de Montigny, L., R. Ling, and J. Zacharias, 2012: The effects of weather on walking rates in nine cities. Environ. Behav., 44, 821-840, https://doi.org/10.1177/0013916511409033.

der Heiden, M., U. Buchholz, and H. Uphoff, 2019: Schätzung der Zahl hitzebedingter Sterbefälle infolge der Hitzewelle 2018 (Estimation of the number of heat-related deaths as a result of the 2018 heat wave). Epidemiologisches Bulletin, No. 23, Robert Koch Institut, 14 pp., https://www.rki.de/DE/ Content/Infekt/EpidBull/Archiv/2019/Ausgaben/23_19.pdf? _blob=publicationFile.

Deutscher Wetterdienst, 2020a: Deutschlandwetter im Jahr 2020: 2020 bestätigt als zweitwärmstes Jahr den fortschreitenden
Klimawandel (Weather in Germany in 2020: 2020 will be the second warmest year, confirming ongoing climate change)., DWD Publ., 7 pp., https://www.dwd.de/DE/presse/pressemitteilungen/ DE/2020/20201230_deutschlandwetter_jahr_2020.pdf;jsessionid= B731E42C841573F943FAE283E5869555.live31083?_blob= publicationFile $\& v=3$.

, 2020b: Heißer Tag (Hot day). DWD Weather and Climate Dictionary, https://www.dwd.de/DE/service/lexikon/Functions/ glossar.html?nn=103346\&lv2=101094\&lv3=101162.

- 2020c: Sommertag (Summer day). DWD Weather and Climate Dictionary, https://www.dwd.de/DE/service/lexikon/ Functions/glossar.html?lv2=102248\&lv3=102522.

Esplin, E. D., J. R. Marlon, A. Leiserowitz, and P. D. Howe, 2019: "Can you take the heat?" Heat-induced health symptoms are associated with protective behaviors. Wea. Climate Soc., 11, 401-417, https://doi.org/10.1175/WCAS-D-18-0035.1.

Field, C. B., and Coauthors, 2012: Managing the Risks of Extreme Events and Disasters to Advance Climate Change Adaptation. Cambridge University Press, 582 pp., https://www.ipcc.ch/site/ assets/uploads/2018/03/SREX_Full_Report-1.pdf.

Fischer, 2005: Aspirations-Psychrometer Assmann. Fischer Product Data Sheet, 4 pp., https://fischer-barometer.de/ media/pdf/52/5f/25/e430101.pdf.

Fischer, E. M., and C. Schär, 2010: Consistent geographical patterns of changes in high-impact European heatwaves. Nat. Geosci., 3, 398-403, https://doi.org/10.1038/ngeo866.

Franck, U., M. Krüger, N. Schwarz, K. Grossmann, S. Röder, and U. Schlink, 2013: Heat stress in urban areas: Indoor and outdoor temperatures in different urban structure types and subjectively reported well-being during a heat wave in the city of Leipzig. Meteor. Z., 22, 167-177, https://doi.org/10.1127/ 0941-2948/2013/0384.

Gil Cuesta, J., J. A. F. van Loenhout, M. C. Colaço, and D. GuhaSapir, 2017: General population knowledge about extreme heat. Int. J. Environ. Res. Public Health, 14, 122, https:// doi.org/10.3390/ijerph14020122.

Grothmann, T., M. Leitner, N. Glas, and A. Prutsch, 2017: A fivesteps methodology to design communication formats that can contribute to behavior change. SAGE Open, 7, 215824401769201, https://doi.org/10.1177/2158244017692014.

Howe, P. D., J. R. Marlon, X. Wang, and A. Leiserowitz, 2019: Public perceptions of the health risks of extreme heat across US states, counties, and neighborhoods. Proc. Natl. Acad. Sci. USA, 116, 6743-6748, https://doi.org/10.1073/pnas.1813145116.

Hsiang, S. M., M. Burke, and E. Miguel, 2013: Quantifying the influence of climate on human conflict. Science, 341, 1235367, https://doi.org/10.1126/science.1235367.

Jacob, D., and Coauthors, 2014: EURO-CORDEX: New highresolution climate change projections for European impact research. Reg. Environ. Change, 14, 563-578, https://doi.org/ 10.1007/s10113-013-0499-2.

Karlsson, M., and N. R. Ziebarth, 2018: Population health effects and health-related costs of extreme temperatures: Comprehensive evidence from Germany. J. Environ. Econ. Manage., 91, 93-117, https://doi.org/10.1016/j.jeem.2018.06.004.

Klok, L., N. Rood, J. Kluck, and L. Kleerekoper, 2019: Assessment of thermally comfortable urban spaces in Amsterdam during hot summer days. Int. J. Biometeor., 63, 129-141, https:// doi.org/10.1007/s00484-018-1644-x.

Kollmuss, A., and J. Agyeman, 2002: Mind the gap: Why do people act environmentally and what are the barriers to proenvironmental behavior? Environ. Educ. Res., 8, 239-260, https://doi.org/10.1080/13504620220145401. 
Koppe, C., S. Kovats, G. Jendritzky, and B. Menne, 2004: Heat-waves: Risks and responses. WHO Health and Global Environmental Change Series 2 Rep., 124 pp., https://apps.who.int/iris/bitstream/ handle/10665/107552/E82629.pdf? sequence $=1 \&$ isAllowed $=y$.

Kunz-Plapp, T., J. Hackenbruch, and J. W. Schipper, 2016: Factors of subjective heat stress of urban citizens in contexts of everyday life. Nat. Hazards Earth Syst. Sci., 16, 977-994, https:// doi.org/10.5194/nhess-16-977-2016.

Lenzholzer, S., and N. Y. van der Wulp, 2010: Thermal experience and perception of the built environment in Dutch urban squares. J. Urban Des., 15, 375-401, https://doi.org/10.1080/ 13574809.2010.488030.

Lin, T.-P., 2009: Thermal perception, adaptation and attendance in a public square in hot and humid regions. Build. Environ., 44, 2017-2026, https://doi.org/10.1016/j.buildenv.2009.02.004.

Mair, J., and M. Whitford, 2013: An exploration of events research: Event topics, themes and emerging trends. Int. J. Event Festiv. Manage., 4, 6-30, https://doi.org/10.1108/17582951311307485.

Matzarakis, A., G. Laschewski, and S. Muthers, 2020: The heat health warning system in Germany-Application and warnings for 2005 to 2019. Atmosphere, 11, 170, https://doi.org/ 10.3390/atmos11020170.

Mayrhuber, E. A.-S., and Coauthors, 2018: Vulnerability to heatwaves and implications for public health interventions-A scoping review. Environ. Res., 166, 42-54, https://doi.org/ 10.1016/j.envres.2018.05.021.

Orbell, S., and P. Sheeran, 1998: 'Inclined abstainers': A problem for predicting health-related behaviour. Br. J. Psychol. Soc., 37, 151165, https://doi.org/10.1111/j.2044-8309.1998.tb01162.x.

Pachauri, R. K., and Coauthors, 2014: Climate Change 2014: Synthesis Report. Cambridge University Press, 151 pp., https:// www.ipcc.ch/site/assets/uploads/2018/02/SYR_AR5_FINAL_ full.pdf.

Rothfusz, L. P., 1990: The heat index "equation" (or, more than you ever wanted to know about heat index). National Weather Service Tech. Attachment SR 90-23, 2 pp., https:// www.weather.gov/media/ffc/ta_htindx.PDF.

Schuster, C., J. Honold, S. Lauf, and T. Lakes, 2017: Urban heat stress. Environ. Res. Lett., 12, 44021, https://doi.org/10.1088/ 1748-9326/aa5f35.

Sharifi, E., and J. Boland, 2018: Limits of thermal adaptation in cities: Outdoor heat-activity dynamics in Sydney, Melbourne and Adelaide. Archit. Sci. Rev., 61, 191-201, https://doi.org/ 10.1080/00038628.2018.1482824.

Shooshtarian, S., P. Rajagopalan, and A. Sagoo, 2018a: A comprehensive review of thermal adaptive strategies in outdoor spaces. Sustainable Cities Soc., 41, 647-665, https://doi.org/ 10.1016/j.scs.2018.06.005.

,-- , and R. Wakefield, 2018b: Effect of seasonal changes on usage patterns and behaviours in educational precinct in Melbourne. Urban Climate, 26, 133-148, https://doi.org/ 10.1016/j.uclim.2018.08.013.

Slovic, P., 1987: Perception of risk. Science, 236, 280-285, https:// doi.org/10.1126/science.3563507.

Snyder, R., and R. Snow, 1984: Converting humidity expressions with computers and calculators. University of California
Division of Agriculture and Natural Resources Cooperative Extension Leaflet 21372, 23 pp.

Thorsson, S., T. Honjo, F. Lindberg, I. Eliasson, and E.-M. Lim, 2007: Thermal comfort and outdoor activity in Japanese urban public places. Environ. Behav., 39, 660-684, https://doi.org/ 10.1177/0013916506294937.

Toloo, G., G. Fitzgerald, P. Aitken, K. Verrall, and S. Tong, 2013: Evaluating the effectiveness of heat warning systems: Systematic review of epidemiological evidence. Int. J. Public Health, 58, 667-681, https://doi.org/10.1007/s00038-0130465-2.

van Loenhout, J. A. F., and D. Guha-Sapir, 2016: How resilient is the general population to heatwaves? A knowledge survey from the ENHANCE project in Brussels and Amsterdam. BMC Res. Notes, 9, 499, https://doi.org/10.1186/s13104-0162305-y.

van Valkengoed, A. M., and L. Steg, 2019: Meta-analyses of factors motivating climate change adaptation behaviour. Nat. Climate Change, 438, 310, https://doi.org/10.1038/ s41558-018-0371-y.

Vanos, J. K., 2015: Children's health and vulnerability in outdoor microclimates: A comprehensive review. Environ. Int., 76, 115, https://doi.org/10.1016/j.envint.2014.11.016.

Wolf, J., W. N. Adger, I. Lorenzoni, V. Abrahamson, and R. Raine, 2010: Social capital, individual responses to heat waves and climate change adaptation: An empirical study of two UK cities. Global Environ. Change, 20, 44-52, https://doi.org/ 10.1016/j.gloenvcha.2009.09.004.

World Health Organization, 2011: Public health advice on preventing health effects of heat: New and updated information for different audiences. WHO Regional Office for Europe Publ., 37 pp., https://apps.who.int/iris/bitstream/handle/10665/ 341580/WHO-EURO-2011-2510-42266-58691-eng.pdf.

__, 2021a: Decade of healthy ageing: Baseline report. WHO Publ., 222 pp., https://www.who.int/publications/i/item/ 9789240017900 .

- 2021b: Heat and health in the WHO European region: Updated evidence for effective prevention (2021). WHO Regional Office for Europe Rep., 176 pp., https://apps.who.int/ iris/bitstream/handle/10665/339462/9789289055406-eng.pdf.

World Meteorological Organization, 2020: WMO statement on the state of the global climate in 2019. WMO Doc. WMO-1248, 44 pp., https://library.wmo.int/doc_num.php?explnum_id=10211.

WürzburgWiki, 2020: Landesgartenschau 2018 (State Garden Show 2018). https://wuerzburgwiki.de/wiki/Landesgartenschau_2018.

Zacharias, J., T. Stathopoulos, and H. Wu, 2001: Microclimate and downtown open space activity. Environ. Behav., 33, 296-315, https://doi.org/10.1177/0013916501332008.

,$- \ldots$, and 2004: Spatial behavior in San Francisco's plazas: The effects of microclimate, other people, and environmental design. Environ. Behav., 36, 638-658, https:// doi.org/10.1177/0013916503262545.

Zander, K. K., W. J. W. Botzen, E. Oppermann, T. Kjellstrom, and S. T. Garnett, 2015: Heat stress causes substantial labour productivity loss in Australia. Nat. Climate Change, 5, 647651, https://doi.org/10.1038/nclimate2623. 